\section{Behavioral Differences in Prepurchase Processes between Purchasers of Flowers for Self Use and for Gift Use}

\author{
Li-Chun Huang ${ }^{1}$
}

ADDITIONAL INDEX wORDs. $t$ test, discriminant analysis, consumer behavior, floral market

SUMMARY. Buying flowers for personal use and for gifts comprises a significant share of the retail flower market. However, data regarding flower purchasing behavior for self use and for gift use are very limited. This study applies a consumer decision process approach to identify behavioral differences in prepurchase behavior of flower purchasing between consumers who mainly purchase flowers for personal use and those who purchase them as gifts. Four hundred ninety-two valid surveys were obtained via purposive sampling, with data collected via a self-administered questionnaire. The statistical results of a stepwise discriminant analysis and $t$ test substantiate that when making flower purchases, self users and gift users exhibit different behavioral patterns in prepurchase behavior with regard to information search, prepurchase evaluation of alternatives, retail channel choice, and store choice. It is clear that self users and gift users are two distinct market segments, and the implication is that for greater marketing efficiency, marketing strategies need to be realigned accordingly.

$\mathrm{T}$ he concept of market segmentation in the floral market has become widely accepted, and a substantial body of research has investigated the characteristics of consumer behavior in several different segments of the market. Robertson and Hahn (1978), for example, examined the demand structure and price elasticity of potted chrysanthemum (Chrysanthemum morifolium) purchases in the market segment of supermarket shoppers; Behe et al. (1992a, b) identified 34 factors in product, consumer, store, and use that influence flower purchases in supermarkets. Behe and Wolnick (1991a) compared behavioral differences among floral consumers segmented on the basis of flower retail outlets and purchase volume. Behe and Wolnick (1991b) also determined that demographic characteristics and floral knowledge differed significantly between fresh flower purchasers and flowering plant purchasers. Although consumer characteristics of many important segments of the

${ }^{1}$ Da-Yeh University, Changhua, 515, Taiwan, R.O.C.

I thank Ying-Lun Lin for assistance with the data collection and Cheryl J. Rutledge for her editorial assistance. Thanks are also due to Neal E. De Vos, Charles Hall, and the anonymous reviewers for their review and insightful comments on an earlier version of this manuscript

E-mail: lc24h@mail.dyu.edu.tw floral market have been studied, very little has been learned about different market segments with respect to the intended use of purchased flowers.

Purchase intention influences consumer consumption of flowers. Personal use (e.g., purchases for ceremonies, celebrations, home or office decoration, spiritual uplifting) and gift giving are the two most prevalent purchase intentions in the floral market. This is exemplified in the following empirical market reports: In Japan, the gift and commercial sectors account for an impressive $80 \%$ of cut flower consumption, whereas the household sector accounts for $20 \%$ (Kim et al., 1999). In Korea, 60\% of cut flower consumption is for ceremonial or celebratory purposes, $20 \%$ for cut flower arrangement instruction, $10 \%$ for home use, and $10 \%$ for office use, whereas $60 \%$ of potted plant consumption is for gifts, $30 \%$ for office or firm decoration, and $\approx 10 \%$ is for home use (Kim et al., 1999). A floral market study by Baourakis et al. (2000) also found that floral products are mostly purchased as gifts, or home or office decoration. Huang (2005) has recently shown that the use of flowers on a daily basis or as gifts puts consumers into the category of heavy flower users. Evidently, personal use and gift giving are the two main motivating forces behind flower purchasing. Thus, to improve the efficiency of marketing strategies in the floral market, behavioral characteristics associated with personal use and gift purchases need to be identified.

Some studies have identified the potential impact of intended use on floral consumer behavior. For example, an Australian consumer survey indicated that consumers with different purchase intentions, regardless of whether they were for home decoration, displayed different emotional values in their flower purchases (Oppenheim, 2000). A qualitative research study based on consumer interviews found that the intended use of flower purchases - namely, personal use or gift giving-influenced the frame of criteria consumers used for selecting their purchase alternatives. When consumers purchased cut flowers for personal use, diversity, price, and color were most highly valued (Baourakis et al., 2000). However, in that study, only emotional value and the selection criteria were compared. For this reason, further study is required to improve our understanding of behavioral differences between self users and gift users in the floral market. This study is designed to fill that void.

Consumer purchase outcome is viewed as a consequence of choice, and there is a complex decision process that determines purchase behavior and purchase outcomes (Blackwell et al., 2006; Engel et al., 1979). Consequently, consumer actions in the decision-making process and the influence of consumers' actions on the process are the structural framework for a consumer behavior study. Many widely used theoretical models are available to illustrate the consumer decision-making process, like the Nicosia, Howard-Sheth, and Engel-Blackwell-Miniard (EBM) models (Blackwell et al., 2006; Howard and Sheth, 1969; Nicosia, 1966). These models all use the consumer decision process approach to interpret consumer behavior.

Because the EBM model, renamed from the well-known EngelKollat-Blackwell (or EKB) model, has the most advanced information in defining consumer behavior, and its analytical units are clearly clarified, it has become one of the most popular theoretical models for 
contemporary researchers to gain insight into consumer behavior (Blackwell et al., 2006; Engel et al., 1979; Rau and Samiee, 1981). The conceptualization of the EBM model has frequently been applied to investigate consumer behavior associated with various products, including general tangible goods, financial services, education, and products on the Internet (Harrison, 2003; Krepapa et al., 2003; Stiber, 2000, 2001).

The EBM model provides the current study with a theoretical base for examining behavioral differences in the prepurchase stages of consumers' flower purchase decision process between self use and gift use purchasers. The model divides the consumer decision process into seven stages: need recognition, search for information, prepurchase evaluation of alternatives, purchase, consumption, postconsumption evaluation, and divestment. Clearly, each stage involves certain distinct acts. The need recognition stage is characterized by purchase motivation, and the factors that trigger consumer purchase motivation are of concern when studying the characteristics of consumer behavior during this stage. During the second stage, the search for information stage, consumers look for information to help them with their purchase decisions. The sources of information used to arrive at a decision and the relative influence of the different sources are the major concerns here. After an information search, consumers are likely to find different alternatives. Therefore, the criteria that consumers use to weigh the alternatives become the main issues for understanding consumer behavior in the third stage of the consumer decision process (i.e., the stage of prepurchase evaluation of alternatives). After consideration, consumers select from among the alternatives in the purchase stage. The consumption, postconsumption evaluation, and divestment stages mainly indicate the postpurchase behavior of consumers, and this includes consumer satisfaction after the purchase decision.

Even though the EBM model divides the consumer decision process into seven stages, the objectives of the current study are achieved by investigating behavioral differences between self users and gift users during prepurchase stages with regard to search for information, prepurchase evaluation of alternatives, and purchase. Because this study uses purchase motivation during the need recognition stage to categorize the sample consumers as self users or gift users of flowers, and because behavior during the consumption, postconsumption evaluation, and divestment stages is usually viewed as the subject of postpurchase behavior, this study does not investigate behavioral differences in the need recognition, consumption, postconsumption evaluation, and divestment stages. This study uses the terms "self users" and "gift users" to distinguish between consumers who mainly purchase flowers for personal use and those who mainly purchase flowers as gifts.

To identify the main behavioral differences in prepurchase processes between self users and gift users of flowers, three objectives are central to this study. They are to identify differences between self users and gift users 1) in the information sources used in the search for information stage, 2 ) in the frame of criteria used in the prepurchase evaluation of alternatives stage, and 3) in the retail channel choice and the criteria for store choice in the purchase stage.

\section{Materials and methods}

QUESTIONNAIRE DESIGN AND MEASUREMENT OF THE VARIABLES. A self-administered questionnaire was used as the instrument for data collection. Consumer identification (e.g., flower self users vs. gift users) was measured with a category-scaled question that asked the participants to do a self-evaluation on the intended use of their flower purchases. Participants who are more likely to purchase flowers for personal use were asked to select the category "personal use," whereas those more likely to purchase flowers for gifts were asked to select the "gift use" category.

Information in the literature review was used to construct the questions for measuring the behavioral characteristics of the search for information, prepurchase evaluation of alternatives, and purchase stages in consumers' flower purchase decision process. Ten questions were developed to evaluate the information sources used in the flower purchase decision. External sources, such as shop windows, newspapers/magazines, word of mouth, mass media, experts, Internet, and direct mail/product catalogs, as well as internal sources, such as personal preference, knowledge, and experience, were all tested in this study. These are reported as potential information sources that consumers use in their purchase decisions (Blackwell et al., 2006). Table 1 lists these question statements.

Another 10 questions were designed to measure the criteria used to explore the prepurchase evaluation of alternatives stage in the flower purchase decision process. Table 2 lists these question statements. Symbolic meaning, longevity, situational value, price discount, product quality, product type, smell, color, freshness, and cultivars are the major concerns of consumers when they ponder their flower purchase options (Behe et al., 1992a, b, 1999; Kelley et al., 2001; Robertson and Chatfield, 1982); thus, these variables were used as the foundation for developing the questions concerning the criteria used in the prepurchase evaluation of alternatives stage in the flower purchase decision process.

After the prepurchase evaluation of alternatives stage, consumers make a final choice from among the alternatives during the purchase stage. However, the final purchase choice is often within the context of the need to select the best retail outlet and to engage in negotiation (Engel et al., 1979). Understanding consumer behavior in these areas is bound to be beneficial when it comes to floral business retail strategies. Consequently, 11 questions were developed to evaluate the retail channel choice and the store choice criteria. To compare behavioral differences between self users and gift users in their choice of purchase channel, traditional flower markets, producers, wholesalers, florists, and the Internet were tested. Various criteria for store choice, including the availability of delivery service, reputation, store atmosphere, store image, convenience, and disposition of sales personnel were also tested in this study (Blackwell et al., 2006). Table 3 lists these question statements.

Data for the characteristics of information source, alternative evaluation criteria, and purchase choice were all measured on the basis of participants' level of agreement with 
Table 1. Summary of the discriminant analysis and $t$ test performed to compare behavioral differences between self users and gift users of flowers in the information sources used in their flower purchase decisions, based on 492 valid questionnaires surveyed from holiday flower markets and florists in Taiwan between 17 Apr. and 2 June 2005.

\begin{tabular}{|c|c|c|c|c|}
\hline \multirow[b]{2}{*}{ Information sources } & \multirow{2}{*}{$\begin{array}{l}t \text { Test for } \\
\text { equality of } \\
\text { group means, } \\
P \text { value }\end{array}$} & \multirow{2}{*}{$\begin{array}{c}\text { Stepwise } \\
\text { discriminant } \\
\text { analysis, standardized } \\
\text { coefficients } \\
\end{array}$} & \multicolumn{2}{|c|}{ Group means ${ }^{\mathrm{z}}$} \\
\hline & & & $\begin{array}{l}\text { Self user }^{\mathrm{y}} \\
(\mathrm{n}=287)\end{array}$ & $\begin{array}{l}\text { Gift user } \\
(\mathbf{n}=205)\end{array}$ \\
\hline $\begin{array}{l}\text { 1. I browse at shop windows } \\
\text { to collect flower purchase information. }\end{array}$ & 0.000 * & 0.599 & 3.32 & 2.94 \\
\hline $\begin{array}{l}\text { 2. I obtain my flower purchase } \\
\text { information from newspapers } \\
\text { or magazines. }\end{array}$ & $0.004^{*}$ & 0.556 & 3.03 & 2.77 \\
\hline $\begin{array}{l}\text { 3. I refer to personal preference } \\
\text { when deciding what to buy when } \\
\text { purchasing flowers. }\end{array}$ & 0.011 * & 0.480 & 4.20 & 4.02 \\
\hline $\begin{array}{l}\text { 4. I obtain flower purchase information } \\
\text { via word of mouth. }\end{array}$ & 0.518 & -0.398 & 3.60 & 3.66 \\
\hline $\begin{array}{l}\text { 5. I obtain flower purchase information } \\
\text { from the mass media. }\end{array}$ & 0.052 & - & 2.79 & 2.61 \\
\hline $\begin{array}{l}\text { 6. I consider the opinion of experts } \\
\text { when deciding what to buy when } \\
\text { purchasing flowers. }\end{array}$ & 0.962 & - & 2.82 & 2.81 \\
\hline $\begin{array}{l}\text { 7. I usually rely on personal knowledge } \\
\text { to decide what to buy when } \\
\text { purchasing flowers. }\end{array}$ & 0.058 & - & 3.94 & 3.82 \\
\hline $\begin{array}{l}\text { 8. I obtain my flower purchase } \\
\text { information from the Internet. }\end{array}$ & 0.861 & - & 3.14 & 3.13 \\
\hline $\begin{array}{l}\text { 9. I decide what to buy based } \\
\text { on my experience } \\
\text { when purchasing flowers. }\end{array}$ & $0.020^{*}$ & - & 4.05 & 3.90 \\
\hline \multirow{3}{*}{$\begin{array}{l}\text { 10. I obtain flower purchase information } \\
\text { from direct mail or product catalogs. }\end{array}$} & 0.568 & - & 3.05 & 2.97 \\
\hline & & & \multicolumn{2}{|c|}{ Group centroid $^{\mathrm{x}}$} \\
\hline & & & 0.204 & -0.286 \\
\hline
\end{tabular}

\begin{tabular}{lccccc}
\hline $\begin{array}{l}\text { Significance test for stepwise } \\
\text { discriminant analysis }\end{array}$ & Eigenvalue & Wilk's $\boldsymbol{\lambda}$ & $\boldsymbol{\chi}^{2}$ & df & $\boldsymbol{P}$ value \\
\hline Stepwise model & 0.059 & 0.945 & 27.762 & 4 & 0.000 \\
\hline
\end{tabular}

${ }^{2}$ Measured on the basis of the participants' level of agreement with the question statements using a 5 -point Likert scale, where 5 is strongly agree, 4 is agree, 3 is neutral, 2 is disagree, and 1 is strongly disagree.

'Categorized by the participants' self-evaluation on a categorized scale about the main intended use of purchased flowers. Self users are those who mainly purchase flowers for personal use, whereas gift users are those who mainly purchase flowers as gifts.

${ }^{x}$ Measured with unstandardized coefficients.

* Significant at $\alpha=0.05$.

the question statements, using a 5 -point Likert scale $(5=$ strongly agree, 4 = agree, 3 = neutral, 2 = disagree, and $\mathrm{l}=$ strongly disagree). Questions in the last section of the questionnaire were related to the measurement of participants' demographics—namely, gender, age, education, occupation, and income.

SAMPLING. Purposive sampling was performed in this study. To encourage the participation of the targeted subjects (i.e., flower self users and gift users), participants were sampled from retail flower outlets (e.g., holiday flower markets and florists). Holiday flower markets are one of the traditional retail flower outlets in Taiwan and are usually large spaces with numerous flower retailers or vendors providing various floral products, including cut flowers, floral bouquets, potted plants, and greens, to name a few, for regular flower purchases. Florists are among the main retail outlets for flowers used as gifts. The holiday flower markets and florists where the survey was conducted were evenly distributed throughout northern, central, and southern Taiwan to ensure the sample is representative of consumers in different geographical regions.

A total of 504 consumers participated in this study. Most of the participants took 10 to $15 \mathrm{~min}$ to complete the self-administered questionnaire. Of the total returned questionnaires, 12 were incomplete and thus were excluded from the analysis. A total of 492 questionnaires were valid for statistical analysis. The survey was conducted between 15 Mar. and 30 June 2005.

Statistical analysis. To identify the main behavioral differences between self users and gift users in prepurchase stages, consumer responses with respect to information sources, criteria used to assess purchase alternatives, retail channel choice, and the criteria used for store choice were analyzed using discriminant analysis. In a discriminant 
Table 2. Summary of the discriminant analysis and $t$ test performed to compare behavioral differences between self users and gift users of flowers with the criteria for evaluating alternatives used in their flower purchase decisions, based on 492 valid questionnaires surveyed from holiday flower markets and florists in Taiwan between 17 Apr. and 2 June 2005.

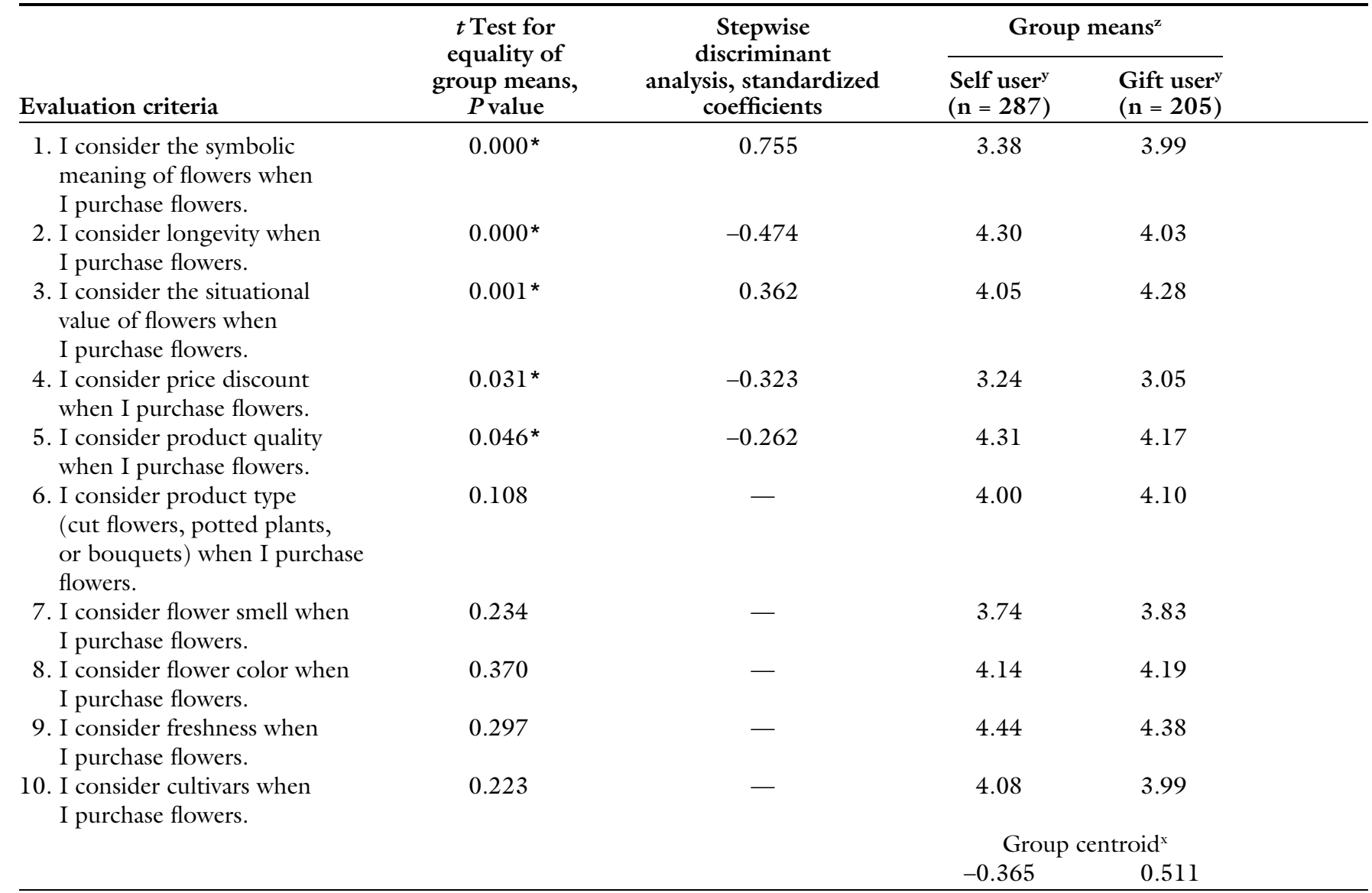

Significance test for the

\begin{tabular}{lllll} 
stepwise discriminant analysis & Eigenvalue & Wilk's $\boldsymbol{P}$ & $\chi^{2}$ & $\mathrm{df}$ \\
\hline
\end{tabular}

\begin{tabular}{lllll}
\hline Stepwise model & 0.187 & 0.842 & 83.626 & 5
\end{tabular}

${ }^{2}$ Measured on the basis of the participants' level of agreement with the question statements using a 5 -point Likert scale, where 5 is strongly agree, 4 is agree, 3 is neutral, 2 is disagree, and 1 is strongly disagree.

yCategorized by the participants' self-evaluation on a categorized scale about the main intended use of purchased flowers. Self users are those who mainly purchase flowers for personal use, whereas gift users are those who mainly purchase flowers as gifts.

${ }^{x}$ Measured with unstandardized coefficients.

${ }^{*}$ Significant at $\alpha=0.05$.

analysis, because the statistics are able to identify the discriminant variables that have the best capability to discriminate between self users and gift users, the main behavioral differences between self users and gift users can readily be identified. The predictive validity of the discriminant variables was assessed, and the significance of the differences was confirmed with a $t$ test. All statistical analyses were performed with SPSS (version 10.0; SPSS, Chicago).

\section{Results and discussion}

Profile of participants. Among the participants, $57.7 \%$ were female and $42.3 \%$ were male. The age distribution was $58.3 \%, 18$ to 30 years;
$25.6 \%, 31$ to 40 years; $8.9 \%, 41$ to 50 years; $5.7 \%, 51$ to 60 years; and $1.4 \%$, older than 60 years. The highest educational levels were $22.6 \%$, graduate school; $62.6 \%$, college or university undergraduate; $12.6 \%$, senior high school; 1.6\%, junior high school; and $0.4 \%$, primary school. A further $0.2 \%$ of the participants did not indicate their educational level. The occupations of the participants were $8.3 \%$, managers; $0.6 \%$, agriculture, forestry, fishing, and animal husbandry workers; $14.4 \%$, service and sales; $7.3 \%$, technicians and assistants; $11.0 \%$, government employees; $0.4 \%$, laborers; $22.2 \%$, professionals; $27.8 \%$, students; and $7.9 \%$,others. A significant proportion of the participants $(45.1 \%)$ reported a monthly income of new Taiwanese dollar (NT\$) 30,000 or less; 38.0\%, between NT\$30,001 and NT\$50,000; 16.6\%, more than NT\$50,000; and $0.2 \%$ of the participants did not provide income information.

According to the self-identification data, 287 participants were defined as flower self users and 205 as flower gift users.

DiFFERENCES IN INFORMATION SOURCES. The analytical results from the stepwise discriminant analysis showed that the differences between self users and gift users with regard to the information source used in the flower purchase decision mainly lay in the variables shop windows, 
Table 3. Summary of the discriminant analysis and $t$ test performed to compare the behavioral differences between self users and gift users of flowers in the retail channel choice and the criteria for store choice in their flower purchase decisions, based on 492 valid questionnaires surveyed from holiday flower markets and florists in Taiwan between 17 Apr. and 2 June 2005.

\begin{tabular}{|c|c|c|c|c|}
\hline \multirow[b]{2}{*}{$\begin{array}{l}\text { Retail channel choice and store } \\
\text { choice criteria }\end{array}$} & \multirow{2}{*}{$\begin{array}{l}t \text { Test for equality } \\
\text { of group means, } \\
P \text { value }\end{array}$} & \multirow{2}{*}{$\begin{array}{c}\text { Stepwise } \\
\text { discriminant } \\
\text { analysis, standardized } \\
\text { coefficients }\end{array}$} & \multicolumn{2}{|c|}{ Group means ${ }^{\mathrm{z}}$} \\
\hline & & & $\begin{array}{l}\text { Self user } \\
(\mathrm{n}=287)\end{array}$ & $\begin{array}{l}\text { Gift user }^{\mathrm{y}} \\
(\mathrm{n}=205)\end{array}$ \\
\hline $\begin{array}{l}\text { 1. I buy flowers from traditional } \\
\text { flower markets. }\end{array}$ & $0.000^{*}$ & 0.775 & 3.67 & 3.15 \\
\hline $\begin{array}{l}\text { 2. The availability of home delivery } \\
\text { service is a criterion in my choice } \\
\text { of store when purchasing flowers. }\end{array}$ & $0.000^{*}$ & -0.573 & 3.07 & 3.47 \\
\hline $\begin{array}{l}\text { 3. Good reputation is a criterion } \\
\text { in my choice of store when } \\
\text { purchasing flowers. }\end{array}$ & 0.111 & 0.292 & 3.94 & 3.82 \\
\hline 4. I buy flowers from producers. & 0.000 * & - & 3.19 & 2.85 \\
\hline 5. I buy flowers from wholesalers. & $0.017^{*}$ & - & 3.30 & 3.02 \\
\hline 6. I buy flowers from florists. & 0.140 & - & 3.57 & 3.69 \\
\hline 7. I buy flowers on the Internet. & 0.066 & - & 2.54 & 2.82 \\
\hline $\begin{array}{l}\text { 8. Store atmosphere is a } \\
\text { criterion in my choice of store } \\
\text { when purchasing flowers. }\end{array}$ & 0.313 & - & 3.93 & 4.01 \\
\hline $\begin{array}{l}\text { 9. Store image is a criterion } \\
\text { in my choice of store when } \\
\text { purchasing flowers. }\end{array}$ & 0.940 & - & 3.67 & 3.66 \\
\hline $\begin{array}{l}\text { 10. Convenience is a criterion } \\
\text { in my choice of store when } \\
\text { purchasing flowers. }\end{array}$ & 0.435 & - & 3.78 & 3.84 \\
\hline 11. Disposition of the sales & 0.375 & - & 4.24 & 4.18 \\
\hline
\end{tabular}
personnel is a criterion in my choice of store when purchasing flowers.

Group centroid ${ }^{\mathrm{x}}$

$0.318 \quad-0.445$

\begin{tabular}{|c|c|c|c|c|c|}
\hline $\begin{array}{l}\text { Significance test for the stepwise } \\
\text { discriminant analysis }\end{array}$ & Eigenvalue & Wilk's $\lambda$ & $\chi^{2}$ & df & $P$ value \\
\hline Stepwise model & 0.142 & 0.875 & 64.978 & 3 & 0.000 \\
\hline
\end{tabular}

${ }^{2}$ Measured on the basis of the participants' level of agreement with the question statements using a 5 -point Likert scale, where 5 is strongly agree, 4 is agree, 3 is neutral, 2 is disagree, and 1 is strongly disagree.

'Categorized by the participants' self-evaluation on a categorized scale about the main intended use of purchased flowers. Self users are those who mainly purchase flowers for personal use, whereas gift users are those who mainly purchase flowers as gifts.

${ }^{x}$ Measured with unstandardized coefficients.

* Significant at $\alpha=0.05$.

newspapers/magazines, personal preference, and word of mouth. The magnitude of the standardized discriminant coefficients indicated that shop windows had the largest discriminating power (discriminant coefficient = 0.599 ) in identifying the differences in the information source between the two groups, followed by newspapers/ magazines (0.556), personal preference $(0.480)$, and word of mouth $(-0.398)$, as indicated in Table 1. The statistical results of the $t$ test confirmed that the group means of these discriminant variables, excluding the word-of-mouth variable, were significantly different between the two types of flower users.

Generally, shop windows, newspapers/magazines, personal preference, and word of mouth all served as the information sources in self users' flower purchase decision because the relative group means of these variables were all above the neutral point on the measurement scale. However, the comparison of group means revealed that self users relied more heavily on shop windows and newspapers/magazines as external information sources than gift users. In fact, it seems unlikely that gift users search for flower purchase information from shop windows or newspapers/magazines, because the group means of these two variables among this group were not only significantly lower than those of the self users, but were also under the neutral point on the measurement scale (Table 1). Compared with shop windows and newspapers/magazines, personal preference was more influential for gift users' flower purchase decision. Although the group mean on the personal preference variable for the flower gift users was statistically lower than that for the flower self users, both group means were high on the measurement scale. Obviously, personal preference was an influential factor in the flower purchase decisions of both groups. Gift users also considered word of mouth to be important in their flower purchase decision, with their reliance on word of mouth about equal to that of self users. 
In sum, when compared with gift users, self users appear to use more external information sources in their flower purchases, especially information from shop windows and newspapers/magazines. These are barely accessed by gift users, who tend to count much more on personal preference and word of mouth in their flower purchase decisions, even though personal preference and word of mouth are also highlighted by the self users.

Usually the initial step in the information search in a purchase decision is an internal information search. If sufficient information is stored in the internal memory system, generally no external information search occurs. Except for inner knowledge, consumer willingness to conduct an external search is also an important factor influencing consumers' search behavior for external information (Engel et al., 1979). Because flower self users are potentially heavy users of flowers, they should have more floral knowledge than the gift users (Behe and Wolnick, 1991b; Behe et al., $1992 a, b)$. Thus, although the statistical results indicated that self users searched for more external information in their flower purchase decisions, it is not reasonable to draw the conclusion that self users have less floral information. The fact that self users and gift users of flowers behave differently in their external information search may result from differences between them in terms of the perceived risk of making incorrect decisions, and in terms of expected gains and perceived time, money, energy, or other costs, which are factors that influence consumer willingness to conduct an external information search (Engel et al., 1979).

DifFerenCES IN THE CRITERIA FOR THE PREPURCHASE EVALUATION OF ALTERNATIVES. Evaluative criteria are the specifications and standards on which consumers assess products. Because the entire group means lay above the neutral point on the measurement scale, it appears that in the prepurchase evaluation of alternatives stage, the product evaluation criteria tested in this study were all important to all participants in both groups.

However, the results from the discriminant analysis provided clear evidence that the main differences between self users and gift users in the alternative evaluation criteria were symbolic meaning, longevity, situational value, price discount, and product quality (Table 2). The statistical results of the $t$ test confirmed that the group means of these variables were significantly different between the two groups. Symbolic meaning almost had the largest power (discriminant coefficient $=0.755$ ) in discriminating between the two groups and was followed by longevity $(-0.474)$, situational value $(0.362)$, price discount $(-0.323)$, and lastly product quality $(-0.262)$. Comparing the group means, it was found that self users putted more focus on the criteria of longevity, price discount, and product quality than gift users, whereas gift users focused more on the criteria of symbolic meaning and situational value.

Evaluative criteria reflect consumers' desired outcomes based on their product choice and use, and are directly influenced by purchase motives (Engel et al., 1979). In other words, in that consumers' expected outcomes and purchase motives are expressed in the evaluative criteria they use in their evaluation and comparison of purchase alternatives, it follows that consumer motives and expected outcomes for flower purchases can be understood from those very evaluative criteria. Self users mainly purchase flowers for personal use, and it is reasonable for them to expect the flowers to have a long vase life and be reasonably priced. Gift users, on the other hand, purchase flowers as gifts and expect them to convey the intention embedded in gift giving. This accounts for the fact that symbolic meaning and situational value are of greater importance to gift users. To a large extent, evaluative criteria are a concrete productspecific manifestation of underlying personal goals - a mechanism that, it is said, makes consumers very resistant to marketers' influence (Engel et al., 1979). Should this be the case, then it is very likely that floral marketers would find it very difficult to influence the evaluative criteria that reflect those underlying consumer goals.

Differences in the Retail CHANNEL CHOICE AND THE CRITERIA FOR STORE CHOICE. During the purchase stage in the consumer decision process, consumers face many different choices before arriving at the final purchase decision (e.g., choices in the purchase channel and type of store) (Engel et al., 1979). The statistical results of the stepwise discriminant analysis determined that in the purchase stage, the main difference between self users and gift users was in the choice of the traditional flower market as the preferred retail channel. The results also showed that, among the store choice criteria, the availability of delivery service and store reputation were the most important (Table 3). The results of statistical analysis from the $t$ test, as presented in Table 3 , showed that the group means of the variables traditional floral market and the availability of delivery service were significantly different between the flower self users and the gift users. The choice of the traditional flower market showed the greatest behavioral difference between self users and gift users during the purchase stage in the flower purchase decision process (discriminant coefficient $=0.775$ ), followed by the store choice criterion of the availability of delivery service (discriminant coefficient $=-0.573)$.

Based on the comparison of the group means, self users exhibited a greater tendency to purchase flowers from the traditional flower market. Regarding the behavioral difference in store choice, gift users seemed to focus on the criterion of availability of home delivery service considerably more than self users (Table 3 ).

Predictive validity of the DISCRIMINANT VARIABLES. To test the capability of classifying the participants in this study on the basis of self users and gift users, the predictive validity of the discriminant equation was investigated.

The discriminant equation formed with the variables shop windows, newspapers/magazines, personal preference, and word of mouth correctly identified a formidable $82.6 \%$ of self users and $32.2 \%$ of gift users. On average, $61.6 \%$ of all participants were successfully classified using this equation (Table 4).

With the discriminant equation formed with the variables symbolic meaning, longevity, situational value, price discount, and product quality, an impressive $77.4 \%$ of self users were correctly distinguished from gift users, and $48.8 \%$ of gift users were 
correctly distinguished from self users. On average, $65.4 \%$ of all participants were correctly classified (Table 5).

With the discriminant equation formed with the variables of retail channel choice toward the traditional flower market as well as the store choice criteria of the availability of delivery service and store reputation, an overwhelming majority of $80.5 \%$ of self users were correctly distinguished from gift users, and $47.8 \%$ of gift users were correctly distinguished from self users. As a total, $66.9 \%$ of all participants were correctly classified (Table 6).

The discriminant equations established in this study had good discriminant power to distinguish self users from gift users, with $77.4 \%$ to $82.6 \%$ of self users being correctly identified. However, the discriminating power to distinguish gift users from self users was relatively poor, with a disappointing $32.2 \%$ to $48.8 \%$ of gift users being identified. This may have resulted from the characteristics of consumer behavior development in the floral market.

Market Facts, Inc. (1989) has identified four stages in the development of flower purchasing behavior. The first stage is the nonuser stage, in which no flowers are purchased. In the second stage, flowers are purchased as gifts, but personal purchases do not occur. In the third stage, personal purchases of flowers increase, whereas gift purchases of flowers remain at the same level or increase. In the final stage, a high proportion of flower gift purchases are made along with regular flower purchases for personal use. Evidently, when consumers begin to become floral consumers, for the most part they purchase flowers as gifts. As users evolve into heavy flower users, flower purchases for personal use occur and increase along with the same or increased flower gift purchases. A floral market segmentation study by Behe and Wolnick (1991a) also demonstrated that heavy flower users buy flowers for personal use or as traditional gifts, whereas light flower users are more likely to buy flowers for obligatory reasons or for traditional gift reasons, but seldom for personal use. From the aspect of consumer behavior development in the floral market, self users in this

Table 4. Predictive validity of the discriminant equation performed with the variables for information sources, including shop windows, newspapers/ magazines, personal preference, and word of mouth, as reported in Table 1, in the classification of self users versus gift users of flowers.

\begin{tabular}{lccc}
\hline & \multicolumn{2}{c}{ Predicted } & Total participants \\
\cline { 2 - 3 } Actual & Self users [n (\%)] & Gift users [n (\%)] & \begin{tabular}{c} 
(n) \\
\hline Self users
\end{tabular} $2^{237(82.6)}$ \\
Gift users & $139(67.8)$ & $50(17.4)$ & 287 \\
\hline
\end{tabular}

An average of $61.6 \%$ of all participants are correctly classified.

Table 5. Predictive validity of the discriminant equation performed with the criteria for the prepurchase evaluation of alternatives, including the variables symbolic meaning, longevity, situational value, price discount, and product quality, as identified in Table 2, in the classification of self users versus gift users of flowers.

\begin{tabular}{lccc}
\hline & \multicolumn{2}{c}{ Predicted } & Total participants \\
\cline { 2 - 3 } Actual & Self users [n (\%)] & Gift users [n (\%)] & (n) \\
\hline Self users & $222(77.4)$ & $65(22.6)$ & 287 \\
Gift users & $105(51.2)$ & $100(48.8)$ & 205 \\
\hline
\end{tabular}

An average of $65.4 \%$ of all participants are correctly classified.

Table 6. Predictive validity of the discriminant equation performed with the variables for the choice of traditional flower markets as the preferred purchase channel and the availability of home delivery service as the criterion for store choice, as identified in Table 3, in the classification of self users versus gift users of flowers.

\begin{tabular}{lccc}
\hline & \multicolumn{2}{c}{ Predicted } & Total participants \\
\cline { 2 - 3 } Actual & Self users [n (\%)] & Gift users [n (\%)] & \\
\hline Self users & $231(80.5)$ & $56(19.5)$ & 287 \\
Gift users & $107(52.2)$ & $98(47.8)$ & 205 \\
\hline
\end{tabular}

An average of $66.9 \%$ of all participants are correctly classified.

study were likely to display two types of purchasing behavior for flowers: the behavior of purchasing flowers for personal use and the behavior of purchasing flowers for gift giving. In other words, self users may have shared certain behavioral characteristics similar with gift users. This might very well explain the difficulty the discriminant equations established in this study had in distinguishing gift users from self users. In contrast, gift users had not yet developed into self users of flowers, nor did they have the behavior characteristics of purchasing flowers for personal use. Hence, self users were more easily distinguished from gift users.

\section{Conclusion}

This study provides evidence that self users and gift users in this study behave differently during prepurchase processes of their flower purchase decision. In the information search stage, self users clearly used a broader range of external information sources in their flower purchase decision. Compared with gift users, self users are more likely to be "walk-in" customers, given their greater propensity to refer to information in shop windows. They are also more likely to refer to newspapers/magazines. When evaluating the alternatives, self users reportedly focused on three product values-longevity, quality, and price-whereas gift users are more likely to be concerned about symbolic meaning and the situational value of floral products. Self users and gift users also differ in their retail channel and store choice behavior. Self users in this study were found to be more likely to purchase flowers from traditional flower markets.

There is no question that floral marketers would be far better off distinguishing between purchases that are for self use and those that are for gift use, and acknowledge that these two types of flower consumers are two fairly distinct market 
segments. They should adjust their marketing strategies accordingly. If the target audience is gift users, then it may very well be inefficient to exhaust advertising budgets in such media as shop windows and newspapers/magazines, because it is evident that gift users seldom search for purchase information in these media. In contrast, if the target audience is self users, or walk-ins, then it may be very beneficial to capitalize on window dressing and well-designed store displays. However, it is clearly apparent that personal preference and word of mouth are important influences for both self users and gift users in this study. There is a need, therefore, for floral marketers to create very favorable purchase experiences for both types of customers to help generate the effects of word of mouthclearly the most widely turned-to external information source among gift users. Extensive consumer work needs to be accentuated to build inner knowledge about and preferences for flowers, largely because this serves as the inner information system that influences consumers in their flower purchase decision.

The behavioral differences among the criteria for evaluating the alternatives reflect the important key differences between self users and gift users in the purchase motives and expected outcomes. When retailing flowers, floral marketers should do more to emphasize the product values of longevity and quality among self users. Benefits in price should also be promoted. At the same time, marketers should target gift users by calling greater attention to the symbolic meaning and situational value of flowers. Because the criteria for evaluating alternatives are highly resistant to the influence of marketers (Engel et al., 1979), the best approach for floral marketers is to address and satisfy these criteria rather than attempt to change the mind-sets of consumers.

Although self users and gift users behave differently in their retail channel and store choices, both types of consumers choose retail stores with a good reputation, whereas gift users are also concerned about whether retail stores offer delivery service. Hence, for the purpose of building a larger customer base in the flower retail market, it seems essential that marketers address the quality and added value of store services.

As an extension of the current study, future studies should attempt to investigate the differences between self users and gift users in their postpurchase behavior (e.g., how they consume the flowers purchased and on what grounds they make their postconsumption evaluation). To be sure, how consumers use the flowers they purchase must affect how satisfied they are with their purchases and how likely they are to repeat that particular purchase behavior in the future. If consumers are highly satisfied, it follows that subsequent purchase decisions should be even easier. Because consumers make a postconsumption evaluation and experience a sense of either satisfaction or dissatisfaction after they have bought and consumed products, they surely store their evaluations in their memories, which they retrieve and refer to when making future decisions. An investigation into postpurchase behavior could provide crucial input to our already enhanced understanding of the best, most efficient way to develop consumer loyalty to products and brands in the floral market.

\section{Literature cited}

Baourakis, G., D. Gerasopoulos, N. Kalofolias, N. Kalogeras, and A. Zoumis. 2000. Marketing research: The case of floral products. Acta Hort. 541:227-232.

Behe, B.K., R. Nelson, S. Barton, C. Hall, C.D. Safley, and S. Turner. 1999. Consumer preferences for geranium flower color, leaf variegation, and price. HortScience 34:740-742.

Behe, B.K., T.A. Prince, and H.K. Tayama. 1992a. Market segmentation of supermarket floral customers. HortScience 27:459-462.

Behe, B.K., T.A. Prince, and H.K. Tayama. 1992b. Analysis of consumer purchases of floral products in supermarkets. HortScience 27:455-459.

Behe, B.K. and D.J. Wolnick. 1991a. Market segmentation of Pennsylvania floral consumers by purchase volume and primary retail outlet. HortScience 26:1328-1331.

Behe, B.K. and D.J. Wolnick. 1991b. Type of floral product purchased and demographic characteristics and floral knowledge of consumers. HortScience 26:414-416.
Blackwell, R.D., P.W. Miniard, and J.F. Engel. 2006. Consumer behavior. 10th ed. Thomson Higher Education, Mason, Ohio.

Engel, J., R.D. Blackwell, and D. Kollat. 1979. Consumer behavior. 3rd ed. Holt, Rinehart, and Winston, New York.

Harrison, T. 2003. Understanding the behavior of financial services consumers: A research agenda. J. Financial Serv. Mktg. 8:6-9.

Howard, J.A. and J.N. Sheth. 1969. The theory of buyer behavior. Wiley, New York.

Huang, L. 2005. Floral product behaviors and their influence on consumer floral purchase frequency. HortTechnology 15:766-771.

Kelley, K.M., B.K. Behe, J.A. Biernbaum, and K.L. Poff. 2001. Consumer preference for edible-flower color, container size, and price. HortScience 36:801-804.

Kim, H.H., Y.J. Kyung, K. Ohkawa, C.H. Pak, and B.H. Kwack. 1999. Flower industry in Korea. Acta Hort. 482: 407-414.

Krepapa, A., P. Berthon, L. Pitt, and A. Caruana. 2003. Industrial marketing and the Internet: Frameworks for assessing communication. J. Asia Pacific Mktg. 2:1-21.

Market Facts, Inc. 1989. Society of American Florists floral marketing report. Soc. Amer. Florists, Washington, DC.

Nicosia, F.M. 1966. Consumer decision processes: Marketing and advertising implications. Prentice-Hall, Englewood Cliffs, N.J.

Oppenheim, P.P. 2000. Segmentation and target marketing in a floral market. Acta Hort. 536:529-536.

Rau, P. and S. Samiee. 1981. Models of consumer behavior: The state of the art. J. Acad. Mktg. Sci. 9:300-316.

Robertson, J.L. and L.H. Chatfield. 1982. Fresh flower merchandising in loose bunches. HortScience 17:593-595.

Robertson, J.L. and D.E. Hahn. 1978. Analysis of demand for potted chrysanthemums in supermarkets. J. Amer. Soc. Hort. Sci. 103:203-206.

Stiber, G. 2000. Characterizing the decision process leading to enrollment in doctoral programs: Theory, application, and practice. J. Mktg. Higher Educ. 10:13-26.

Stiber, G. 2001. Characterizing the decision process leading to enrollment in master's programs: Further application of the enrollment process model. J. Mktg. Higher Educ. 11:91-107. 